\title{
O USO DE SOFTWARES NA APRENDIZAGEM BASEADA EM PROBLEMAS
}

\author{
Software Usage in Problem Based Learning
}

\author{
Paula Patrícia Barbosa Ventura ${ }^{1}$
}

\begin{abstract}
Resumo: A presente investigação teve como objeto: $O$ uso de softwares na Aprendizagem Baseada em Problemas (PBL) proporciona momentos de aprendizagem ativa? Assim, este artigo objetivou analisar se o uso de softwares na PBL proporciona momentos de aprendizagem ativa, destacando as características dessa metodologia de ensino na prática docente. De natureza qualitativa, do tipo estudo de caso, a pesquisa foi realizada com um professor do curso de graduação tecnológica em Processos Ambientais de um Instituto Federal. Como instrumentos, recorreu-se a um questionário de sondagem, à observação e à entrevista. Para a análise de dados, iniciou-se com as questões de menor amplitude, bem como se definiram códigos iniciais ou subsequentes. Fases como ordenação, classificação e análise propriamente dita do material também subsidiaram a análise. Posteriormente, foram triangulados os dados, sendo estes ancorados pelo paradigma interpretativo. Ainda que o software em si não propicie a aprendizagem ativa, o direcionamento do docente fez todo o sentido para que o discente se tornasse protagonista de seu aprendizado, uma vez que a escolha das atividades precisa fazer sentido para o discente, caso contrário não propiciará esse tipo de aprendizagem. Destarte, tal conclusão comprova a importância do uso pedagógico da tecnologia, recaindo este uso nos momentos de indagação, questionamento e elaboração conjunta de saberes que ela (a tecnologia) pode promover e não apenas no uso pelo uso.
\end{abstract}

Palavras-chave: Softwares. Aprendizagem Baseada em Problemas. Prática Docente.

Abstract: The present investigation had as its object: Does the use of software in Problem Based Learning (PBL) provide moments of active learning? Thus, this article aimed to analyze whether the use of software on PBL provides moments of active learning, while highlighting the characteristics of this teaching methodology in teaching practice. The research was of a qualitative nature, case study type, and was carried out with a professor of the technological graduation course in Environmental Processes at a Federal Institute. As instruments, a survey questionnaire, observation and interviews were used. For data analysis, it started with the smallest extent questions, as well as defining initial or subsequent codes. Phases such as ordering, classification and analysis of the material itself also supported the analysis. Thus, the data were triangulated, being then anchored by the interpretive paradigm. Although the software itself does not provide active learning, the teacher's guidance made perfect sense for the student to become the protagonist of his learning, since the choice of the activities needs to make sense to the student, otherwise it will not provide this type of learning. Thus, such a conclusion testifies the importance of the pedagogical use of technology, with its use reflecting on the moments of inquiry, questioning and joint elaboration of knowledge that it (the technology) can promote and not only in the use itself.

Keywords: Software. Problem Based Learning. Teaching Practice.

\footnotetext{
${ }^{1}$ Doutora em Educação Brasileira pela Universidade Federal do Ceará. Professora do Instituto Federal de Educação, Ciência e Tecnologia do Ceará. Orcid: https://orcid.org/0000-0003-1405-0634 Email: paula.ventura@ifce.edu.br.
} 


\section{Introdução}

Pesquisas apontam que a utilização de softwares nos processos de ensino induz o aluno ao protagonismo, bem como favorece interações reais com o objeto do conhecimento na perspectiva do aprender fazendo (ALVES; COUTINHO, 2016; FONTES; VALENTIM, MENDES NETO, 2014; TRINDADE; FIOLHAIS, 2003; TRINDADE et al, 2001). Ainda assim, não é qualquer software e sua categorização não é consensual. Por vezes, a expressão software de modelagem não aparece nas discussões ou, então, aparece como sinônimo de software de simulação (TAJRA, 2019; VIDAL; MAIA; SANTOS, 2002; OLIVEIRA; COSTA; MOREIRA, 2001).

A modelagem é comumente utilizada para analisar o comportamento de fenômenos reais ou hipotéticos e consiste em três fases: a construção de um modelo que represente aspectos relevantes do sistema sendo estudado; experimentação e análise do modelo criado e; comparação do modelo construído com sistemas reais. A simulação faz parte do processo de modelagem e envolve a fase dois de execução do modelo e análise dos resultados (BARANAUSKAS et al, 1999). A diferença está em quem escolhe o fenômeno a estudar e quem desenvolve o seu modelo. No primeiro, é o usuário quem escolhe o fenômeno, desenvolve o seu modelo e implementa-o no computador. Já no segundo, isso é feito a priori e é fornecido ao usuário (VALENTE, 1999).

Quando o vocábulo 'modelagem' aparece, grande parte das pesquisas ${ }^{2}$ faz referência à duas tendências da educação matemática: a resolução de problemas e a modelagem matemática (FERREIRA; SILVA, 2019; ANDREATTA; ALLEVATO, 2019; SODRÉ; GUERRA, 2018; GONÇALVES; LIMA, 2017). No entanto, o termo empregado no presente artigo diz respeito a modelagem computacional, pois fará referência a atividades que façam uso do computador e expressem "o modelo de um fenômeno/processo, com o objetivo subsequente de explorar possíveis consequências do modelo e reavaliar, a partir do feedback da simulação, não apenas o modelo construído, mas o próprio conhecimento sobre o fenômeno/processo-alvo" (BARANAUSKAS et al, 1999, p. 51).

Neste artigo, a locução software de modelagem e de simulação estará associada a aprendizagem baseada em problemas (PBL) por considerar a possibilidade de os alunos buscarem soluções para problemas reais ou simulados, demonstrando envolvimento e pensamento produtivo, buscando a visão global de um fenômeno, seu questionamento e investigação, o que pode caracterizar uma aprendizagem mais autoral e ativa.

A aprendizagem ativa diz respeito a elaboração, teorização e sistematização do conhecimento aprendido, tomando por base a autonomia, engajamento, interesse e maior participação do aluno no processo de aprender. Se os discentes discutem e buscam descobrir as respostas aos problemas propostos, provavelmente, sentir-se-ão envolvidos com as atividades realizadas, precisando estas fazerem sentido ao universo do educando.

Nesse sentido, questiona-se: $\mathrm{O}$ uso de softwares de modelagem e de simulação na PBL proporciona momentos de aprendizagem ativa? Que características da PBL são de aprendizagem ativa e se sobressaem quando o professor faz uso de softwares? Portanto, o objetivo deste artigo é analisar se o uso de softwares na PBL proporciona momentos de aprendizagem ativa, destacando as características dessa metodologia de ensino na prática docente.

\footnotetext{
${ }^{2}$ Em levantamento realizado no portal da CAPES (15/08/2020) utilizando os descritores software de modelagem e aprendizagem baseada em problemas, restritos a artigos em português, apareceram 52 resultados, sendo a maioria na área da Matemática. Outros estudos se voltam à área de Gestão do Conhecimento e Negócios.
} 
$\mathrm{O}$ artigo proposto se justifica pela necessidade de promover reflexões sobre o uso da tecnologia nos processos de ensinar e a sua inserção e discussão nos currículos, primordialmente sobre a resolução de problemas por meio do uso de softwares, tendo como ponto de partida uma aprendizagem centrada no aluno. Quando o discente é capaz de utilizar a tecnologia em seu percurso de aprendizagem, no caso, softwares que possibilitem a criação de modelos e a sua manipulação (realização idêntica de ações à realidade), ele mesmo define o caminho e as formas de aprender. Justifica-se ainda, evidenciar as práticas realizadas por um docente que utilizou a tecnologia durante toda a disciplina, até mesmo por sua natureza curricular. No caso analisado, a tecnologia diz respeito à softwares como o Stella e o Climate Rapid Overview and Decision Support ${ }^{3}$ (C-Roads) como aliados à disciplina de Métodos Computacionais Aplicados à Área Ambiental. O recorte dos dados diz respeito a uma pesquisa ${ }^{4}$ a nível de doutorado cuja defesa ocorreu em 2019.

Estruturalmente, o artigo está dividido em cinco partes. Após as considerações introdutórias, discute-se no referencial teórico os softwares de modelagem e simulação e a aprendizagem baseada em problemas. Em seguida, a metodologia utilizada. Posteriormente, apresentam-se os resultados e, por último, as conclusões.

\section{Softwares de modelagem e simulação}

Em sentido amplo, a modelagem refere-se a uma linguagem para expressar formalmente um modelo que represente determinado conhecimento, enquanto o modelo é a representação propriamente dita (BARANAUSKAS et al, 1999). Expresso de outro modo, o modelo seria a formalização dos conhecimentos prévios e sistematizados do estudante, passíveis de análise e depuração, não havendo uma sequência rígida de passos para o processo de aprendizagem. Segundo Valente (1999), a modelagem exige certo grau de envolvimento na definição e representação computacional do fenômeno. No caso da simulação, não, necessariamente, pois o que vai diferenciar esse envolvimento é o tipo de simulação, se aberta ou fechada.

$\mathrm{Na}$ simulação aberta, o aluno é estimulado a descrever ou implementar aspectos do fenômeno, requerendo que ele se envolva com esse fenômeno. "Nesse envolvimento com o fenômeno, o aprendiz elabora uma série de hipóteses e ideias que deverão ser validadas por intermédio do processo de simulação" (VALENTE, 1999, p.80). Quando aberta, a simulação pode fornecer algumas situações já previamente definidas e outras complementadas pelo usuário. $\mathrm{Na}$ simulação fechada não há esse envolvimento e o aluno é pouco desafiado a elaborar, testar e validar as hipóteses. Nesse tipo de simulação, o fenômeno é previamente implementado pelo computador e "os valores de alguns parâmetros são passíveis de serem alterados pelo aprendiz" (VALENTE, 1999, p.80).

Mas independente se abertos ou fechados, os softwares de simulações possibilitam o aprender fazendo, ainda que em maior ou menor grau, por meio de atividades de exploração, investigação e descoberta, tendo como base o computador. Tais características também se aplicam aos softwares de modelagem quando a referência é aprender fazendo, construindo e protagonizando.

$\mathrm{Na}$ atualidade, outras tecnologias se tornaram aliadas ao processo de ensino e aprendizagem e o computador comumente é substituído pelas tecnologias móveis, visando à

\footnotetext{
${ }^{3}$ Disponível em: https://www.climateinteractive.org/tools/c-roads/ Acesso em: 09 mai 2021.

${ }^{4}$ Foi aprovada pelo Comitê de Ética da Universidade Federal do Ceará, lócus onde a pesquisadora cursou seu doutorado. O parecer está sob o número 2.584.742.
} 
interação homem-máquina/tecnologia digital, sendo assim os modelos a serem construídos podem ser facilmente desenvolvidos por outras tecnologias que não o computador. Esta interação denominada de sujeito-objeto pode favorecer a aprendizagem desde que a ênfase seja no sujeito e não na tecnologia, pois se considera a "construção e não a instrução; o controle do estudante e não o controle do sistema; a individualização é determinada pelo aluno e não pelo sistema e há feedback rico gerado a partir da interação com o ambiente de aprendizagem e não pelo sistema" (BARANAUSKAS et al, 1999, p. 51). O importante é que o aluno não limite a sua aprendizagem ao uso do software, mas sim desenvolva a sua capacidade de agir sobre e não se deixe ser instruído pelo sistema, pois os ambientes de modelagem e simulação permitem a (re)construção do objeto de estudo.

Se por um lado, os softwares de modelagem e simulação permitem o estudante criar ou simular a solução de um problema, fornecendo-lhe liberdade de ação, por outro, lhe é exigido reflexão para compreender a situação que está sendo explorada, bem como a tomada de decisão, requerendo dos alunos mais envolvimento com sua aprendizagem. Quando se questiona se o uso de softwares de modelagem e simulação favorece a aprendizagem ativa, a resposta deve permear características como interesse intrínseco do aluno na solução de um problema, reflexão para as (des)construções, envolvimento do discente com o objeto de estudo, protagonismo para a (re)criação e proposição de novas soluções para problemas existentes.

A relação entre o uso de softwares e a aprendizagem baseada em problemas será definida pelo docente, uma vez que não é o software que criará a melhor situação de aprendizagem, tão pouco a aprendizagem ativa. Ainda que o discente tenha responsabilidade pelo próprio aprendizado, é o docente quem deve criar condições para que aquele se envolva com a proposta de atividades. É ele, com seu conhecimento e experiência, quem definirá os recursos a serem utilizados, bem como saiba aliá-los aos conteúdos e objetivos a serem alcançados.

Se o objetivo for desencadear a aprendizagem ativa, Vickery (2016) defende a importância de o discente participar do planejamento docente, exercendo a sua criatividade e a reflexão. Esta participação produz alunos mais focados e conscientes de si e dos outros como alunos, bem como desenvolve uma disposição pela curiosidade, perseverança, confiança e reflexão. A autora reitera, também, a ideia de que as atividades devem ser desafiadoras, criativas e colaborativas, ensejando o questionamento e o debate, possibilitando aos alunos externalizarem seus pensamentos e valores.

No caso deste artigo, a atividade principal da disciplina analisada foi desenvolver um modelo computacional com o software de modelagem Stella visando à solução de um problema. Outra atividade que, também, fez parte da disciplina foi o desenvolvimento de uma oficina utilizando o software de simulação C-Roads objetivando discutir conceitos sobre o clima. Conforme será visto, a interação do aluno com o sistema foi fundamental e requereu deste questionamentos consigo e com os colegas, envolvimento com a proposta desenvolvida, elucidação de dúvidas e maior participação de todos no decorrer do processo, promovendo uma aprendizagem mais autoral e ativa.

\section{Aprendizagem baseada em problemas}

A aprendizagem na PBL deve ser obtida de situações contextualizadas da vida do discente (seja pessoal ou profissional) e retornar ao seu cotidiano com soluções e conhecimentos sistematizados. Boud e Feletti (1997) enumeram seis características da PBL: utiliza-se de materiais de estímulo para os alunos refletirem sobre os problemas ou questões 
que lhes são propostas; apresenta o problema como uma simulação de prática profissional ou situação de vida real; incentiva o pensamento crítico e fornece recursos para ajudar os alunos a aprenderem, definindo e tentando resolver o problema; alunos atuam colaborativamente para a resolução do problema, explorando informações dentro e fora da aula, sendo o professor um conhecedor no problema e capaz de facilitar a aprendizagem do grupo; estudantes identificam suas necessidades de aprendizagem e utilizam adequadamente os recursos e, por último, são capazes de reaplicar o que aprenderam à situação original e avaliar o percurso que realizaram em busca da solução do problema.

Das seis características ora apresentadas, destacam-se duas: a colaboração e o professor como conhecedor do(s) problema(s). Boud e Feletti (1997) destacam a colaboração na PBL, quando os alunos se ajudam e são recompensados, aumentando a qualidade da aprendizagem e o efeito motivacional, uma vez que se sentem envolvidos com situações reais e não apenas com conceitos teóricos, aprendendo a resolver problemas eficazmente. Se os alunos são recompensados, provavelmente, seus interesses aumentam e, se estes crescem, o professor pode elevar o nível dos problemas a serem resolvidos, desafiando e pondo-os à prova, de modo que atuem e intervenham em seu meio.

Gil (2017) destaca a existência de várias estratégias para desenvolver a PBL, sendo as mais utilizadas o método de caso e as simulações, trazendo muitas vantagens à aprendizagem, tais como: a compreensão dos assuntos, a retenção e a transferência do conhecimento, a responsabilidade pela própria aprendizagem, o desenvolvimento de habilidades interpessoais e do espírito de equipe, a automotivação, o relacionamento entre os estudantes, a interdisciplinaridade, o estabelecimento de novas formas de relacionamento entre professores e estudantes e aprendizado no decorrer da vida.

Como limitações, Gil (2017) enumera: redução do tempo destinado ao ensino dos fundamentos das disciplinas; desempenho de novos papéis pelos estudantes e professores; formulação de problemas apropriados; exigência de muito mais tempo do que os procedimentos tradicionais; necessidade de mais recursos humanos e materiais; necessidade de intenso monitoramento, envolvimento do conjunto de professores do curso e complexidade de avaliação do aproveitamento dos estudantes.

Especificamente sobre as simulações, diz-se que são estratégias que colocam os alunos em situações próximas da realidade e que "[...] possibilitam um feedback imediato das consequências de comportamentos, atitudes e decisões" (GIL, 2017, p.188), constituindo numa atividade interessante para o discente, fazendo com que se envolvam mais facilmente com essa estratégia do que qualquer outra, podendo o professor utilizar com inúmeros objetivos e sem o uso do computador (GIL, 2017). Tais objetivos podem ser: estimular a reflexão acerca de determinado problema; construir e levantar hipóteses; tornar conceitos abstratos mais concretos; promover um clima de descontração entre os estudantes; engajar estudantes em tarefas com alto nível de interatividade; promover o raciocínio crítico; favorecer o autoconhecimento; desenvolver a empatia; analisar situações de conflito; desenvolver habilidades para a solução de problemas; e estimular o conhecimento do mundo natural mediante a interação com modelos que não poderiam ser inferidos por intermédio da observação direta (GIL, 2017, p. 190).

Ao relacionar a aprendizagem compartilhada com a figura do professor, as ações e posições dos discentes e do docente se entrelaçam (aluno-líder; aluno-professor e vice-versa), podendo ser negociadas, corroborando a ideia de Lee e Tan (2004) ao afirmarem que a colaboração fornece aos participantes a negociação de posições. Essa negociação envolve dois 
movimentos recursivos: um dialético com o outro (pessoa ou ideia) e um reflexivo com o eu (IDEM, IBIDEM).

Barrows e Tamblyn (1980) destacam que, embora o professor tenha responsabilidade considerável no início da PBL, ao proporcionar experiências e as orientações necessárias, é o aluno quem assumirá a responsabilidade total de sua aprendizagem, identificando suas necessidades educacionais, a melhor forma de aprender, o ritmo de seu aprendizado e a sua capacidade de avaliar o que foi aprendido. Neste formato de aprendizagem, o discente é responsável também por buscar referências atualizadas ou recursos de aprendizagem para atender às suas necessidades e o que aprende não se limita à sala de aula.

Como desvantagens da PBL, Barrows e Tamblyn (1980) destacam que inúmeros recursos devem estar à disposição do aluno para que possam perseguir as próprias necessidades de aprendizagem. É visto como desvantagem porque os autores argumentam que o currículo deve ser desestruturado para permitir que o aluno gaste tempo usando os recursos disponíveis como melhor lhe convém, atendendo seus objetivos educacionais. Outra desvantagem refere-se à avaliação individualizada.

Deve-se abandonar a avaliação em massa e considerar uma que privilegie os objetivos de aprendizagem do discente, para que ele mesmo crie critérios de sucesso. Os desafios da aplicação da PBL variam do uso de simulações para a compreensão do problema ao uso de diferentes ferramentas de avaliação para analisar o processo de resolução de problemas ou raciocínio, sendo a busca e o estudo de informações necessários para entender os mecanismos responsáveis pelo problema (BARROWS; TAMBLYN, 1980).

Como na aprendizagem ativa o discente assume o protagonismo de sua aprendizagem, Barrows e Tamblyn (1980) destacam que é necessário haver maturidade e disciplina de sua parte, pois, ao trabalhar com problemas desconhecidos, o aluno é forçado a desenvolver habilidades de resolução de problemas, diagnóstico e raciocínio dedutivo, devendo obter informações e sugestões acerca do problema. Se o problema é desconhecido, requer tempo para que o aluno amadureça, entenda sua terminologia, significados, a dinâmica social e psicológica do problema, o que pode servir como elemento propulsor para que a aprendizagem aconteça.

Apesar das concepções de Barrows e Tamblyn datarem de um período nada atual, são autores pioneiros e possuem influência significativa na PBL nas Ciências da Saúde. Percebe-se, também, uma preocupação antiga para que o discente se torne um participante ativo de sua aprendizagem, desde o estabelecimento de objetivos à avaliação do que foi aprendido, podendo a PBL ser analisada, contrastada e referenciada em diversos contextos, situações e áreas do conhecimento.

\section{Metodologia}

De natureza qualitativa, a pesquisa se caracterizou como um estudo de caso, pois se pretendeu uma compreensão mais detalhada dos fenômenos da vida real, considerando as condições contextuais (YIN, 2010), ou seja, detalhes das ações de um único docente, com procedência em situações específicas de seu trabalho, portanto, de uma instância singular em ação.

A pesquisa deu-se no Instituto Federal de Educação, Ciência e Tecnologia do Ceará, campus Camocim, lócus que a pesquisadora atuou como docente. Os dados foram coletados nos semestres 2016.2 e 2017.1. No estudo maior (Tese de Doutorado) participaram quatro professores e a escolha se deu mediante um questionário. Para este artigo, o recorte diz 
respeito apenas aos dados de um docente, caracterizado aqui como professor quatro (P4), denominação dada na tese. A disciplina teve como critério aquela que estava sob sua responsabilidade e era de curso superior. O quadro um (1) contém suas informações, que foram coletadas pelo questionário.

Quadro 1 - Informaç̃es do professor 4 (P4)

\begin{tabular}{|c|c|}
\hline $\begin{array}{l}\text { Formação Acadêmica } \\
\text { de P4 }\end{array}$ & $\begin{array}{l}\text { - Bacharel em Engenharia Ambiental (Instituto Nacional de Pesquisas da } \\
\text { Amazônia - INPA) } \\
\text { - Mestre em Biologia de Água Doce e Pesca Interior - Limnologia (INPA) } \\
\text { - Doutor em Biotecnologia (Universidade Federal do Amazonas - UFAM) }\end{array}$ \\
\hline $\begin{array}{l}\text { Idade Cronológica/ } \\
\text { Tempo de Docência }\end{array}$ & $\begin{array}{c}43 \text { anos } \\
\text { Entre } 6 \text { a } 10 \text { anos de docência }\end{array}$ \\
\hline $\begin{array}{l}\text { Disciplina/ Carga } \\
\text { Horária/ Semestre/ } \\
\text { Curso }\end{array}$ & $\begin{array}{c}\text { Métodos Computacionais Aplicados à Área Ambiental/ 80h (4ºmestre) } \\
\text { Tecnólogo em Processos Ambientais }\end{array}$ \\
\hline
\end{tabular}

Fonte: VENTURA (2019).

A disciplina Métodos Computacionais Aplicados à Área Ambiental foi dividida em duas partes: uma teórica $(40 \mathrm{~h})$ e uma prática $(40 \mathrm{~h})$. Como o laboratório de informática estava em reforma e não havia sido concluído antes do início da disciplina, toda a parte teórica foi finalizada na etapa I da disciplina, restando para a etapa II somente a parte prática.

Outros instrumentos de coleta de dados foram utilizados, como a observação sistemática e a entrevista semiestruturada. P4 foi acompanhado num período de dois meses e em momento algum, as observações e entrevistas objetivaram avaliar o professor como um exímio docente ou não, assim como elencar erros e acertos pedagógicos das aulas ministradas. $\mathrm{O}$ acompanhamento foi em um dia da semana apenas (eram dois dias semanalmente), pois um dos horários coincidiu com as atividades de ensino da pesquisadora.

Para este artigo, o foco foi analisar se o uso de softwares na PBL proporcionou momentos de aprendizagem ativa destacando as características dessa metodologia de ensino na prática do docente investigado. Em momentos formais, identificou-se que a metodologia predominante na prática de P4 foi a PBL. Após essa identificação, buscou-se na literatura as características dessa metodologia que sinalizavam a aprendizagem ativa.

Em conversas informais com o professor antes e após as aulas, foi possível identificar as preferências metodológicas e suas intencionalidades ao utilizar determinada metodologia em detrimento da outra. As anotações foram registradas em diário de campo e $\mathrm{P} 4$ teve ciência dos registros, conforme o Termo de Consentimento Livre Esclarecido (TCLE), que se entregou, devidamente assinado, a ele.

Após o período de observação, iniciou-se a análise desse instrumento de coleta. O que não pôde ser compreendido nesse período ou, então, que requereu maior aprofundamento, foi inserido em questões pontuais da entrevista.

Para a análise dos dados de um estudo de caso, tomou-se como orientações as de Yin (2010) de definir códigos iniciais ou subsequentes, refletindo o significado das palavras e frases exigindo da pesquisadora uma justificativa analítica para tais significados. Tanto para as observações quanto para a entrevista foram criados códigos, como por exemplo $\mathrm{T}$ para as tecnologias e M para metodologias.

Aliada às ideias de Yin (2010), utilizou-se os pressupostos de Minayo (2016), ao sequenciar as fases de análise de dados em ordenação, classificação e análise propriamente dita do material, respectivamente, conduzindo a uma busca da lógica peculiar e interna do 
professor pesquisado, sendo esta a construção essencial da pesquisa. Depois que os dados foram ordenados e codificados, foram organizados e preparados para a fase seguinte, a classificação, sinalizando a análise propriamente.

As análises foram subsidiadas pelo paradigma interpretativo, oportunizando a pesquisadora voltar ao campo e P4 validar ou não o olhar científico daquela, expondo pontos de vista. Esse paradigma possibilita que a análise seja respaldada tanto à luz de teóricos quanto pela visão do sujeito (MOREIRA; CALEFFE, 2006). Posteriormente, foi feita a triangulação dos dados, na qual se estabeleceram as relações entre os instrumentos de coleta, verificando-se os pontos de convergência, divergência e de regularidades, o que permitiu a pesquisadora proceder a uma análise global e precisa sobre o objeto de estudo (MOREIRA; CALEFFE, 2006).

\section{Resultados e discussão dos dados}

Os resultados foram apresentados como eventos e referentes às anotações do diário de campo e às transcrições da entrevista. Foram transcrições literais, não havendo correções gramaticais correspondentes à norma culta.

\subsection{Descrição e análise da prática de P4}

Sua metodologia caracterizou-se predominantemente pela resolução de problemas por meio de modelagens computacionais ao fazer uso de softwares específicos ${ }^{5} \operatorname{como}_{\text {o Stella } e}$ C-Roads. P4 utilizou a pesquisa em diversos momentos, pois compreendia que o docente não deveria fornecer tudo "mastigadinho" ao aluno, e a sua utilização faria com que o discente descobrisse, com autonomia, o conhecimento. Nos momentos de pesquisa, o papel do professor foi estimular o aluno a procurar materiais, fomentando a iniciativa discente e eximindo o fornecimento de informações prontas.

A disciplina Métodos Computacionais Aplicados à Área Ambiental teve como objetivo capacitar o aluno para modelagem computacional do ambiente e, por este motivo, suas aulas práticas visaram à realização de exercícios de modelagem, tais como: modelagem do fluxo de água de um lago, modelagem do crescimento linear, exponencial e logístico da dinâmica de populações, modelagem do sistema presa-predador no Lotka-Voltera (modelando espécies) e modelagem computacional do modelo simplificado e complexo do ciclo global de carbono (parte terrestre e oceânica).

Especificamente sobre à avaliação, esta foi explicitada no início da disciplina, quando P4 discorreu sobre as atividades a serem realizadas (individual e em grupo), a apresentação dos algoritmos para a resolução de equações diferenciais ordinárias (EDO) por meio de métodos numéricos (Euler e Runge Kutta), bem como o evento Clima Mundial por meio de oficina.

As aulas práticas da disciplina seguiram o fluxo: exercícios no software Stella visando desenvolver o modelo dinâmico de simulação aproximado da realidade, tira-dúvidas dos alunos ( $\mathrm{P} 4$ atendia individualmente e no grupo), com algumas proposições e questionamentos, não fornecendo a resposta, mas possibilitava reflexões para que eles encontrassem o caminho pretendido, finalizava a aula com encaminhamentos para o encontro seguinte e, ao final da

\footnotetext{
${ }^{5}$ Os softwares que não estão linkados não possuem site oficial nem versão para download.

${ }^{6}$ Expressão de $\mathrm{P} 4$.
} 
disciplina, todos os alunos entregaram o modelo simulado em pendrive a $\mathrm{P} 4$, bem como desenvolveram a oficina previamente orientada.

O não fornecimento da resposta correta após o aluno manifestar sua dúvida é fundamental para que ele reflita, organize seu pensamento e formule a própria resposta, sendo este momento o de estudar as informações para entender os mecanismos responsáveis pelo problema. A elaboração do modelo dinâmico foi uma atividade realizada durante toda a disciplina pelos alunos, ainda que não tivessem chegado ao resultado correto, como afirma P4:

\begin{abstract}
Não teve nenhum estudante até hoje que conseguiu resolver o problema das taxas, que não é um problema que está evidente. Tem que ter uma conscientização do todo, visualizar melhor. Tem que ir atrás, tem que estudar, tem que ler, tem que testar, tem que rodar o sistema várias vezes, tem que ver o que tá acontecendo, tem que fazer um procedimento de variáveis (Evento 1 - Entrevista realizada no dia 25/10/2017).
\end{abstract}

Apesar de o professor ter importância considerável no início da PBL (BARROWS; TAMBLYN, 1980), no segundo momento é o aluno quem assume a responsabilidade total de sua aprendizagem, sendo este o papel desempenhado por P4. Na etapa I, ele forneceu toda a fundamentação teórica e, na etapa II a turma assumiu o comando de sua aprendizagem, mas sempre com sua supervisão. Ainda que o software fosse necessário para resolver o problema das taxas, exigiu-se do discente habilidades de compreensão, de reflexão, de depuração e maturação para elucidar o problema proposto.

Em outro momento da entrevista, P4 menciona que a maior dificuldade dos alunos foi a falta de base Matemática, "[...] não sendo um problema do Instituto Federal, mas do Ensino Médio". Em suas palavras, a grande vantagem da disciplina é que o computador faz toda a resolução matemática, ficando a cargo do discente entender o fenômeno e as taxas a serem colocadas para o modelo dinâmico rodar. No evento citado, o 1, P4 compreende que a aprendizagem do aluno depende somente dele mesmo e que, apesar de evidenciar as dificuldades dos alunos, fala que

[...] eu jogo o conhecimento lá em cima no pico do Everest, mas eu cobro e acho que é o suficiente do conhecimento pra ele ter uma formação profissional evidente [...] se um dia ele precisar, ele vai saber onde procurar, ele vai saber onde buscar suporte porque ele teve uma visão daquilo, apesar dele não ter, de repente, atingido lá o cume (Evento 2 - Entrevista realizada no dia 25/10/2017).

Mesmo evidenciando o fato de que trabalha com níveis elevados de complexidade, ao afirmar que "joga o conhecimento lá em cima", deixa claro que cobra o suficiente para que os alunos tenham boa formação profissional, ou seja, mostra todas as possibilidades e níveis de compreensão, fazendo com que o aluno tenha uma visão geral do conteúdo e o caminho que os discentes podem escolher para que sua aprendizagem aconteça. A ação de P4 se assemelha a ideia de Boud e Felletti (1997) ao afirmarem que na PBL o professor pode elevar o nível dos problemas, desafiando-os e pondo-os à prova.

Apesar da falta de conhecimentos matemáticos dos discentes, P4 pontua também:

Existe muita coisa a ser aprendida na área ambiental. É uma visão muito particular. Eu acho que você não tem que maximizar em cima daquilo que você não sabe. Têm pessoas muito boas na área de Biologia, de Sistemática, tá, outras são melhor na área de Física. Como a área ambiental, ela é transdisciplinar, multidisciplinar, de múltiplas ações, tá, então o estudante tem que maximizar o que ele tá mais familiarizado (Evento 3 - Entrevista realizada no dia 25/10/2017). 
Ainda que a Matemática seja importante para a disciplina analisada, o aluno deve ter consciência de que outras disciplinas são importantes na área ambiental como P4 frisou no evento 3. Essa descoberta fará com que o aluno esteja avivado durante todo o percurso e não se julgue incapaz, pois uma disciplina não desmerece as demais que necessitam de outras disciplinas. A sua vontade de aprender, aliada à autoconfiança, deve perdurar em todo o percurso de aprendizagem, fazendo com que possuam maturidade e disciplina para atuarem como protagonistas (VICKERY, 2016).

Destaca-se que (in)diretamente a disciplina trabalha numa perspectiva interdisciplinar entre as áreas ambiental e matemática se aproximando de ideias já discutidas na literatura, quando Gil (2017) pontua que a PBL promove a interdisciplinaridade entre várias áreas e a aplicação prática delas requer a compreensão teórica de seus respectivos conceitos.

Como a metodologia de $\mathrm{P} 4$ foi fundamentalmente a de resolver problemas por meio da modelagem computacional, uma ação cotidiana complementar às já pontuadas nos eventos $1 \mathrm{e}$ 3 , respectivamente, (acreditar na capacidade dos alunos, ainda que eles não chegassem no resultado desejado, bem como reconhecer as dificuldades), foi a de valorizar as produções intelectuais, no caso, o desenvolvimento o modelo dinâmico, o tempo de reflexão dos alunos, prolongando-o, e não fornecia a resposta correta, como nos eventos a seguir:

P4 solicitou aos alunos a elaboração de um modelo dinâmico de simulação (do ciclo
do carbono) aproximado da realidade utilizando o software Stella. P4 acompanhou o
desenvolvimento dos modelos de cada aluno, dispondo-se a tirar dúvidas e fazendo
com que eles percebessem seus próprios erros (Evento 4 - Diário de Campo, 03/02;
10/02; $17 / 02 ; 24 / 02 ; 03 / 03 / 2017$ ).
[...] A aluna chegou para P4 e disse não alcançar o resultado. Após ser orientada por
P4, que instigava seu raciocínio com proposições, ela por si só percebeu que 0.6 e
0,6 no sistema de modelagem eram taxas diferentes e que o ponto e a vírgula faziam
toda a diferença. Depois P4 disse à turma: "não darei o site agora para que vocês
possam brincar mais um pouco no programa" (Evento 5 - Diário de Campo,
$24 / 02 / 2017$ ).

No evento 4, o tempo fornecido por P4, para que o aluno refletisse sobre seus erros e encontrasse a resposta, fez com que o estudante estabelecesse relação entre a fala do professor e as suas representações mentais, significando, assim, a materialidade do processo de conhecimento. A relação estabelecida foi com os materiais disponibilizados com antecedência e dos quais, comumente, os alunos faziam uso na sala de aula (no caso, no laboratório de informática).

Apesar da PBL exigir mais tempo na resolução do problema, visto por Gil (2017) como desvantagem, no caso analisado foi visto como vantagem, uma vez que propiciou a aluna maior envolvimento com a atividade e exigiu dela outras habilidades mentais, além da compreensão, como análise, associações (interdisciplinaridade) e comparações.

No evento 5, uma análise pode ser realizada, também oriunda do tempo fornecido por $\mathrm{P} 4$, a do aluno elaborar hipóteses, com suporte no acompanhamento do professor, congruente ao que aconteceu. A aluna, por si, percebeu que apenas uma taxa, a de 0.6 ou 0,6 , era a correta, o que a possibilitou encadear seu pensamento, com base em uma orientação mais próxima e atenta por parte de P4. 
É viável que esse tempo de espera reflexiva não seja curto nem longo, mas ideal para que os alunos não se dispersem e possam organizar as ideias. Fez questão de deixá-los mais tempo sem a resposta, quando disse: "[...] não darei o site agora para que vocês possam brincar mais um pouco no programa". Na PBL, os alunos são forçados a desenvolverem habilidades de resolução de problemas, diagnóstico e raciocínio dedutivo, devendo obter informações e sugestões acerca do problema (BARROWS; TAMBLYN, 1980).

Os eventos referenciados mostram que a aprendizagem ativa não depende apenas da iniciativa dos alunos, mas de uma participação direta do professor, ou seja, de um engajamento ativo de sua parte no processo de aprendizagem de seu aluno. Nesse sentido, pontua: "[...] não dou aula para o aluno ter nota, aprovação, mas para trabalhar comigo" (Evento 6 - Diário de Campo, 03/02/2017).

P4 tem consciência que ser professor não é apenas ministrar o conteúdo, mas preparar o aluno para outros fins como, por exemplo, desenvolver pesquisa. Em vários momentos informais e durante a entrevista afirmou que se considerava pesquisador antes de ser professor. Esse engajamento ativo do professor é decifrado, ainda, pela necessidade que o aluno tem de dar um retorno do que foi realmente aprendido, de devolver à realidade social todo o entendimento consolidado na instituição formadora. Se o aluno constrói conhecimento novo e é capaz de ressignificá-lo, será possível intervir naquilo que conhece com profundidade e com o devido conhecimento de causa.

Quando P4 é questionado se teriam outros softwares a serem utilizados que não fosse o Stella, responde que sim e cita vários. Como respondeu em várias questões diferentes da entrevista, compactou-se as respostas em um único evento:

existem softwares de modelagem dinâmica bem interessantes, como o software Simile, [...] que é um software proprietário como o Stella, mas ele é pra Linux; o software $V \operatorname{sim},[\ldots]$ que é um sistema alemão, utilizado pro $C$-Roads e que utiliza a mesma linguagem de diagramatização via Forrest; o software OpenModelica ${ }^{7}$ [...] que funciona como um grande simulador e [...] é um software muito poderoso pra muitas outras coisas; [...] tem um sisteminha chamado gazebo ${ }^{8}$, que é muito legal, que ele faz simulações, sistema de simulações em três dimensões (Evento 7 Entrevista realizada no dia 25/10/2017).

De forma direta e fazendo referência à aprendizagem, perguntou-se:

Pesquisadora: Que outras tecnologias poderiam ser utilizadas em suas aulas e que despertassem a aprendizagem dos alunos? (Evento 8 - Entrevista realizada no dia 25/10/2017).

P4: Tem uma última parte que tu não participastes, né, quando a gente utiliza o método, né, de produção numérica que faz uma análise de erro, que é o método de Euler, de um sistema dinâmico.

Pesquisadora interrompeu: Outro?

P4: O sistema dinâmico que a gente tá rodando no Stella, ele utiliza lá três formas de você criar o número de futuro. A gente tem o $n$ - 1 , que é os dados do passado, tem o

\footnotetext{
${ }^{7}$ Disponível em: https://www.openmodelica.org/ Acesso em: 09 mai 2021.

${ }^{8}$ Disponível em: http://gazebosim.org/ Acesso em: 09 mai 2021.
} 
$n$ né, tem o $n 1$, que é o dado daquele momento, e o $n+1$ que é o dado que vem do futuro. Tem que fazer a projeção do dinâmico, né,

Pesquisadora interrompeu: Que eu não vi?

P4: E que a gente não tem. A gente não tem esse dado projetado pro cenário de acordo com as informações futuras. Tem uns artifícios matemáticos, né, e o Stella oferece três opções pro estudante. Ele vai clicar no botãozinho, não vai querer muita matemática que tá por trás porque o software não exige isso, tá, tem o método de Euler, o método de Runge Kutta segunda ordem, método de Runge Kutta quarta ordem que no final da disciplina pra dar um gostinho dos estudantes fazerem programas e mexendo com rotinas computacionais eu utilizo a linguagem Python, que é uma linguagem que reduz muito o código e muito fácil o acesso e eles acabam criando esses algoritmos, né. [...] É mais uma brincadeira de fechamento da disciplina. Eles têm acesso a um outro patamar computacional. É uma outra tecnologia.

Ao favorecer novas discussões sobre o mesmo assunto, rotinas computacionais, P4 favorece o enfoque de um assunto sob diferentes ângulos, no caso do Stella e dos métodos supracitados, oportunizando aos alunos que se façam conscientes dos problemas que aparecem com suporte nas informações obtidas. Reitera-se o fato de que essa atitude possibilitou também aos alunos a formulação de novas ideias acerca do objeto de estudo, no caso, as rotinas computacionais, mediante experiências com o software Stella.

Apesar da disciplina exigir o uso da tecnologia em todo o seu trajeto, pela própria natureza curricular, nem todos os alunos têm domínio desse uso como afirma P4:

P4: [...] nós temos dentro do Instituto Federal aquele estudante que é analfabeto digital, né, e temos aquele estudante que é mais racker do que um dia qualquer um já foi. É um rapazinho que tem grande capacidade de entender como as coisas funcionam, tá. E você tem esses dois estudantes numa mesma sala de aula, daí o conceito de tecnologia fica diferente e a forma com que essa tecnologia vai ser apropriada é completamente difusa, tá. Não tem uma conexão, tá. Então, depende muito a forma como o estudante tá usando, tá se relacionando com isso. [...] a tecnologia não é mais importante. $\mathrm{O}$ importante é a informação. $\mathrm{O}$ importante é o conhecimento. [...] o que tá por trás. [..] é apropriação da informação, do conhecimento. Acho que é a grande chave (Evento 9 - Entrevista realizada no dia 25/10/2017).

P4 compreende, também, que mais importantes são a informação e o conhecimento que estão por trás do uso da tecnologia, sendo esta uma concepção pedagógica da tecnologia. Esta concepção demonstra que P4 não utiliza a tecnologia em sala de aula somente por uma exigência da disciplina e de forma aleatória (uso pelo uso).

Este último, quando P4 diz num trecho da entrevista "[...] ele começa a manipular os modelos, começa a manipular as situações extremamente complexas, começa a ver que o desafio é a ideia, é o fenômeno e não o computador". Ou seja, compreende a tecnologia como:

P4: [...] uma ferramenta aliada ao desenvolvimento de algo que está na abstração dele. Então, ele começa a ver que a tecnologia nada mais é do que uma ferramenta, tá, pra algo muito maior. A ideia da tecnologia, do computador, do desenvolvimento do computador, das tecnologias colocadas no computador é fantástica, tá, que jamais vai alcançar (Evento 10 - Entrevista realizada no dia 25/10/2017). 
A conscientização que $\mathrm{P} 4$ possui sobre a tecnologia como meio e não como fim faz com que o aluno perceba isso sozinho. Ao ser capaz de planejar situações para que essa percepção aconteça, dá ao discente a possibilidade de aprender em ritmo próprio, desvelando suas fragilidades e potencialidades por meio da relação tecnologia e educação.

É interessante que na PBL a resolução de problemas pode ocorrer individualmente ou em grupo, havendo diferenças quanto a sua finalidade, como é observado no próximo evento:

Pesquisadora: Uma das avaliações da sua disciplina foi o desenvolvimento de um modelo dinâmico de simulação aproximado da realidade utilizando o software Stella, bem como uma oficina utilizando o simulador C-Roads, sendo o primeiro realizado individual e o segundo em grupo. De que forma essas atividades favorecem a aprendizagem do aluno? (Evento 11 - Entrevista realizada no dia 25/10/2017).

P4: [...] com relação ao objeto da avaliação, eu preciso saber se o estudante aprendeu alguma coisa, por isso tem o caráter individual. Ele tem que comprovar que ele aprendeu, porque, quando tá trabalhando em grupo, é muito fácil você se maquiar em cima dos colegas. Então, ele vai ter essa participação individual pra mostrar pra que que ele está ali e o que ele está fazendo, tá. E na avaliação em grupo, é a interação dos sistemas, porque a gente trabalha com sistêmica, então a gente tem que ver a sua parte mediada no todo, tá. Então isso é muito importante. Que ele tenha aí esse caráter também de compreender que a decisão que ele tá trabalhando é uma tomada em grupo, né. Isso aí com relação à nota final. Se ele conseguiu fazer, chegou num patamar de conhecimento e eu sei que ele conseguiu aplicar esse conhecimento com um fim maior, que é a decisão final, o consenso. Claro que o computador vai fazer o consenso do modelo, tá. É o consenso de grupo discutido. É uma tendência a partir de uma discussão anterior, mas a resposta vem do modelo, tá. E com relação ao aprendizado, realmente parte desse princípio que individualizando vai ter o caráter que eu fiz, tá. E ele analisando em grupo vai ter importância que o que eu fiz vai ter a resolução de um problema não é só meu. Então, eu acho que esse é o pontinho que... né.

Para $\mathrm{P} 4$, a atividade avaliativa individual demonstra que foi o aluno quem fez, que ele foi o autor da ação reflexiva. Já numa atividade de grupo, P4 tem consciência de que um aluno pode se beneficiar do saber do outro, não tendo, portanto, como diagnosticar com precisão quem foi o autor da produção intelectual. Ao equilibrar os dois tipos de atividades, o professor precisa deixar claro para o aluno o objetivo da atividade e o que espera dele como elaborador de seu conhecimento.

Pode esclarecer que, individualmente, estão em jogo a iniciativa pessoal, o interesse atualizado e instigante e a produtividade cumulativa e sistemática. Já na atividade em grupo, apesar da dificuldade de todos colaborarem de maneira igual, o grupo precisa saber que a finalidade pode ser a troca de ideias, tomada de decisões, definição de acordos e desacordos, debate, consenso e atitudes diferentes (quando assuntos polêmicos).

Destaca o fato de que, em grupo, a tomada de decisão é fundamental, mostrando saber que a resolução final deve levar em consideração o consenso, possibilitando a negociação de posições. Essa negociação envolve, segundo Lee e Tan (2004), dois movimentos recursivos quando discutem a colaboração na PBL: o dialético com o outro e um reflexivo com o eu. A fala de P4 caminha nessa direção de recursividade, de comunhão com o outro e com o sistema (ao mencionar a interação dos sistemas). 
Especificamente sobre a atividade em grupo, foi desenvolvida uma atividade prática em formato de oficina utilizando o simulador C-Roads cujas regras, instruções, papéis que cada equipe deveria desempenhar, bem como estratégias de negociação e avaliação foram esclarecidas no início. P4 esclareceu que o objetivo desta atividade foi fazer com que os alunos descobrissem, por si, como as políticas propostas poderiam influenciar o sistema climático em tempo real.

No dia da realização das oficinas, última semana da disciplina, ao mediar as apresentações, $\mathrm{P} 4$ confrontou os resultados das taxas climáticas entre os grupos. À medida que os discentes foram se apresentando, P4 foi levantando questões e confrontando os resultados dos grupos entre si, promovendo indiretamente uma competição de quem tinha acertado o quê. Esse papel desempenhado por P4, não apenas demonstrou interesse na dúvida dos alunos explicando diversas vezes a intencionalidade e importância da atividade para a disciplina. Não foi um tira-dúvidas apenas pela formalidade do processo de aprendizagem, mas equacionou todas as inquietudes dos discentes antes e ao longo da proposta da oficina.

Apesar de ter sido uma atividade rápida, promoveu engajamento de toda a turma, pois assumiram papéis diversificados e cada grupo se responsabilizou por uma função específica. Esse gerenciamento fez com que não se detivessem apenas ao papéis de aluno, mas de orientador, de líder, de professor, de mediador e de gerenciador de todo o processo, fortalecendo as relações interindividuais. O professor também assumiu as mesmas funções e, por vezes, seu papel se diferenciou apenas pelo conhecimento acerca do assunto. A seguir, outras considerações.

\section{Conclusões}

O objetivo deste artigo foi analisar se o uso de softwares na PBL proporciona momentos de aprendizagem ativa, destacando as características dessa metodologia de ensino na prática docente. Ainda que o software em si não propicie esse tipo de aprendizagem, independente se de modelagem ou de simulação (aberta ou fechada), o direcionamento do professor fez todo o sentido para que o aluno se tornasse protagonista de seu aprendizado, destacando-se por ser conhecedor do problema, do contrário, não saberia explicar onde os alunos deveriam chegar.

À medida que os dados foram sendo analisados, destacou-se características de aprendizagem ativa, explicitando muito mais o teor pedagógico da tecnologia que propriamente o tecnológico. Ou seja, a análise não recaiu no uso pelo uso, mas nos processos de indagação, questionamento, perguntas e elaboração conjunta de saberes que a tecnologia proporcionou. Se a análise tivesse se detido no uso da ferramenta, provavelmente, os alunos não teriam apresentado autonomia, engajamento com as atividades propostas nem interesse de realização, pois em alguns momentos $\mathrm{P} 4$ afirmou que os alunos não possuíam familiaridade com a ferramenta nem base matemática, apesar do software Stella realizar toda a parte matemática.

As duas atividades da disciplina propiciaram a construção e sua (re)elaboração, uma vez que os estudantes foram capazes de buscar fontes, discutir entre os pares, de criar, testar, duvidar dos resultados e tirar as próprias conclusões. Destaca-se que a atividade precisa fazer sentido para o discente, antagonicamente não propiciará a aprendizagem ativa. Se o que aluno desenvolve, em seu processo formativo, fizer parte de sua realidade, provavelmente, terá mais chances de haver envolvimento, autoria e gerência do que deseja aprender. O planejamento de uma atividade visando à aprendizagem ativa, precisa ser coparticipada com o discente e possuir uma intencionalidade clara, tanto no que diz respeito ao objetivo a ser alcançado ao 
final, quanto nas habilidades discentes pretendidas e nos meios utilizados para a sua realização.

Esclarece-se, ainda, que não se trata dos alunos decidirem "o que" fazer (autonomia e iniciativa) e "fazer" (produtividade), cabendo ao professor apenas providenciar. No caso específico, um software que propiciasse a produtividade do aluno, mas sim ter conhecimento de causa das potencialidades que o Stella e o C-Roads poderiam desencadear na aprendizagem. Como sugestão para trabalhos futuros, sugere-se analisar como se dá a aprendizagem ativa em turmas do Ensino Médio, uma vez que o foco dos Institutos Federais é a Educação Básica.

\section{Referências}

ALVES, Lynn.; COUTINHO, Isa Jesus (org.). Games e educação: nas trilhas da avaliação baseada em evidências. In: Jogos digitais e aprendizagem: fundamentos para uma prática baseada em evidências. Campinas, SP: Papirus, 2016. p. 9-15.

ANDREATTA, Cidimar; ALLEVATO, Norma Suely Gomes. Um cenário das pesquisas envolvendo Resolução de Problemas em edições do CIEM. Educação Matemática Pesquisa. São Paulo, v. 21, n. 1, abr. 2019. Disponível em: https://revistas.pucsp.br/emp/article/view/37019. Acesso em: 09 maio 2021.

BARANAUSKAS, Maria Cecilia Calani et al. Uma taxonomia para ambientes de aprendizado baseados no computador. In: VALENTE, José Armando Valente (org.). $\mathbf{O}$ computador na sociedade do conhecimento. Campinas: UNICAMP/NIED, 1999.

BARROWS, Howard; TAMBLYN, Robyn. Problem-based learning: an approach to medical education. New York: Springer Publishing Company, 1980.

BOUD, David; FELETTI, Grahame. The Challenge of Problem Based Learning. 2.ed. London: Kogan Page, 1997.

FERREIRA, Pamela Emanueli Alves; SILVA, Karina Alessandra Pessoa da. Modelagem matemática e uma proposta de trajetória hipotética de aprendizagem. Bolema. São Paulo, vol.33, n.65, pp.1233-1254, 2019. Disponível em:

https://www.scielo.br/pdf/bolema/v33n65/1980-4415-bolema-33-65-1233.pdf Acesso em: 09 maio 2021.

FONTES, Laysa Mabel de Oliveira; VALENTIM, Ricardo Alexsandro de Medeiros; MENDES NETO, Francisco Milton. Modelagem de um sistema multiagente de apoio à pbl utilizando a metodologia mas-commonkads+. Holos. Rio Grande do Norte, v. 5, p. 222-245, 2014. Disponível em: https://repositorio.ufrn.br/jspui/handle/123456789/29353. Acesso em: 09 maio 2021.

GIL, Antonio Carlos. Didática do ensino superior. 1 ed. 10 reimpr. São Paulo: Atlas, 2017.

GONÇALVES, Paulo Gonçalo Farias; LIMA, Ravenia Adail Silva Vieira. O ensino de estatística por meio da pesquisa: uma experiência à luz da modelagem matemática. Holos. Rio Grande do Norte, v. 2, p. 190-198, 2017. Disponível em:

http://www2.ifrn.edu.br/ojs/index.php/HOLOS/article/view/3514 Acesso em: 09 maio 2021. 
LEE, Moira; TAN, Oon-Seng. Collaboration, dialogue, and critical openness through problem-based learning processes. Enhancing thinking through Problem-based Learning approaches: International Perspectives, 2004.

MINAYO, Maria Cecília de Souza (org.); DESLANDES, Suely Ferreira; GOMES, Romeu. Pesquisa social: teoria, método e criatividade. Petrópolis, RJ: Vozes, 2016.

MOREIRA, Herivelto; CALEFFE, Luiz Gonzaga. Metodologia da pesquisa para o professor pesquisador. Rio de Janeiro: DP\&A, 2006.

OLIVEIRA, Celina Couto de.; COSTA, José Wilson da.; MOREIRA, Mércia. Ambientes informatizados de aprendizagem: produção e avaliação de software educativo. Campinas, SP: Papirus, 2001.

SODRÉ, Gleison de Jesus Marinho; GUERRA, Renato Borges. O ciclo investigativo de modelagem matemática. Educação Matemática Pesquisa, São Paulo, v. 20, n. 3, jan. 2019. Disponível em: https://revistas.pucsp.br/emp/article/view/39865. Acesso em: 09 maio 2021.

TAJRA, Sanmya Feitosa. Informática na educação: o uso de tecnologias digitais na aplicação das metodologias ativas. 10. ed. São Paulo: Érica, 2019.

TRINDADE, Jorge et al. Ambientes gráficos tridimensionais como ferramentas físico-químicas no ensino e na aprendizagem das ciências. In: ENCONTRO NACIONAL DE EDUCAÇÃO EM CIÊNCIAS, 8., 2001, Ponta Delgada, Açores. Proceedings [...] Ponta Delgada: Universidade dos Açores, 2001, p. 391-403. Disponível em: https://estudogeral.sib.uc.pt/handle/10316/40296. Acesso em: 09 maio 2021.

TRINDADE, Jorge; FIOLHAIS, Carlos. Física no computador: o computador como uma ferramenta no ensino e na aprendizagem das ciências físicas. Revista Brasileira de Ensino da Física. São Paulo: Sociedade Brasileira de Física. v.25, n. 3, p. 259-272, 2003.

Disponível em: http://www.sbfisica.org.br/rbef/pdf/v25_259.pdf Acesso em: 09 maio 2021.

VALENTE, José Armando Valente. Análise dos diferentes tipos de softwares usados na educação. In: VALENTE, José Armando Valente (org). O computador na sociedade do conhecimento. Campinas: UNICAMP/NIED, 1999.

VENTURA, Paula Patrícia Barbosa. Indicadores de metodologias ativas com suporte das tecnologias digitais: estudo com docentes do Instituto Federal de Educação, Ciência e Tecnologia do Ceará. 2019. 195f. Tese (Doutorado) - Universidade Federal do Ceará, 2019. Disponível em: http://www.repositorio.ufc.br/handle/riufc/40528. Acesso em: 09 maio 2021.

VICKERY, Anitra; ANSELL, Carrie; ANSELL, Keith; COLLIER, Chris; DIGBY, Rebecca; FFIELD, Mary; FOSTER, Tor; GARSIDE, Darren. Aprendizagem ativa nos anos iniciais do ensino fundamental. Porto Alegre: Penso, 2016.

VIDAL, Eloisa Maia; MAIA, José Everardo Bessa; SANTOS, Gilberto Lacerda. Educação, informática e professores. Fortaleza: Demócrito Rocha, 2002. 
Revista de Educação, Ciência e Tecnologia

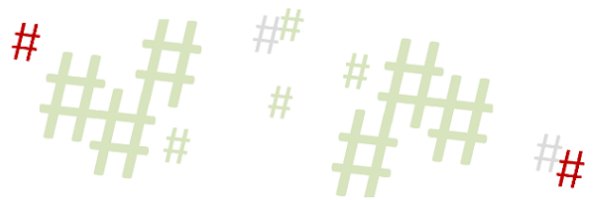

YIN, Robert. Estudo de caso: planejamento e métodos. 4 ed. Porto Alegre: Bookman, 2010.

Recebido em setembro de 2020.

Aprovado em maio de 2021. 